\title{
Microfabricated Air-core Toroidal Inductor In Very High Frequency Power Converters
}

\author{
Lê Thanh, Hoà; Nour, Yasser; Han, Anpan; Jensen, Flemming; Ouyang, Ziwei; Knott, Arnold
}

Published in:

IEEE Journal of Emerging and Selected Topics in Power Electronics

Link to article, DOI:

10.1109/JESTPE.2018.2798927

Publication date:

2018

Document Version

Peer reviewed version

Link back to DTU Orbit

Citation $(A P A)$ :

Lê Thanh, H., Nour, Y., Han, A., Jensen, F., Ouyang, Z., \& Knott, A. (2018). Microfabricated Air-core Toroidal Inductor In Very High Frequency Power Converters. IEEE Journal of Emerging and Selected Topics in Power Electronics, 6(2), 604-613. https://doi.org/10.1109/JESTPE.2018.2798927

\section{General rights}

Copyright and moral rights for the publications made accessible in the public portal are retained by the authors and/or other copyright owners and it is a condition of accessing publications that users recognise and abide by the legal requirements associated with these rights.

- Users may download and print one copy of any publication from the public portal for the purpose of private study or research.

- You may not further distribute the material or use it for any profit-making activity or commercial gain

- You may freely distribute the URL identifying the publication in the public portal 


\title{
Microfabricated Air-core Toroidal Inductor In Very High Frequency Power Converters
}

\author{
Hoa Thanh Le, Student Member, IEEE, Yasser Nour, Member, IEEE, Anpan Han, Member, IEEE, \\ Flemming Jensen, Ziwei Ouyang, Member, IEEE, and Arnold Knott Member, IEEE
}

\begin{abstract}
Miniaturization of power supplies is required for future intelligent electronic systems e.g. internet of things devices. Inductors play an essential role, and they are by far the most bulky and expensive components in power supplies. This paper presents a miniaturized microelectromechanical systems (MEMS) inductor and its performance in a very high frequency (VHF) power converter. The MEMS inductor is a siliconembedded air-core toroidal inductor, and it is constructed with through-silicon vias, suspended copper windings, silicon fixtures, and a silicon support die. The air-core inductors outperform the silicon-core inductors with higher quality factor at higher frequency. This is verified by small-signal measurements. A 20 turn air-core inductor achieved an inductance of $44.6 \mathrm{nH}$ and a quality factor of 13.3 at $33 \mathrm{MHz}$, while a silicon-core inductor with the same geometry has a quality factor of 9 at $20 \mathrm{MHz}$. A DC-DC class-E boost converter is designed and implemented using the fabricated MEMS air-core inductor and a highperformance $65 \mathrm{~V}$ gallium nitride field effect transistor. The VHF converter achieved a peak efficiency of $78 \%$ at the input voltage of 6.5 $\mathrm{V}_{\mathrm{DC}}$. The MEMS inductor can carry $1 \mathrm{~A}$ RMS AC current at $33 \mathrm{MHz}$ and delivers $10.5 \mathrm{~W}$ to the output.
\end{abstract}

Index Terms - Microelectromechanical systems, inductor, DCDC power converters, zero voltage switching, gallium nitride.

\section{INTRODUCTION}

$\mathrm{P}$ OWER supplies are essential sub-systems for modern intelligent electronic devices and systems. They are found in customer electronics, light emitting diode (LED) lightings, and internet of things (IoTs) [1]-[3]. Size, weight, life time, and cost are critical for such applications. While most electronic systems have been advanced rapidly with a dramatic decrease in size and cost, power supply technology is lagging behind. Power supplies are still bulky, inefficient, and costly [4]-[6]. Power supply in package (PwrSiP) [5], [6] and power supply on chip (PwrSoC) [5]-[10] are the vision of power supplies with high efficiency, high power density, and low cost.

This project is a part of TinyPower project which is funded by Innovation Fund (No. 67-2014-1). The first two authors contributed equally to this work.

H. T. Le is with National Center for Micro- and Nanofabrication (DTU Danchip) and DTU Electrical Engineering (DTU Electro), Technical University of Denmark (DTU), 2800 Kongens Lyngby, Denmark. (email: hoalet@dtu.dk)

A. Han and F. Jensen are with DTU Danchip (email: anph@dtu.dk, fj@danchip.dtu.dk)

Y. Nour, Z. Ouyang, and A. Knott are with DTU Electro (e-mail: ynour@elektro.dtu.dk, zo@elektro.dtu.dk, akn@elektro.dtu.dk)
Developing integrated power converter requires miniaturization of energy-storing elements and makes them compatible with the processing flow of integrated circuits. Increasing the switching frequency to the very high frequency range (VHF) $(30 \mathrm{MHz}-300 \mathrm{MHz})$ allows the inductance values needed for PwrSoC to drop to tens of nanohenries $(\mathrm{nH})$.

Taking advantages of microelectromechanical systems (MEMS) fabrication technologies, miniaturized silicon-based inductors can be fabricated with high quality factor, high operating frequency, and high inductance thus enabling their usage in power supplies as energy storage elements. There are two categories of microfabricated inductors: magnetic-core and non-magnetic core inductors. Magnetic-core inductors are typically fabricated with magnetic thin films and twodimensional (2D) windings such as spiral inductor [11], [12] and race track inductor [13]-[16]). Three-dimensional (3D) windings such as solenoid inductor [17], [18], and toroidal inductor [19], [20] are also possible. High inductance density can be achieved with high permeability core materials, but excessive core loss at VHF operating range is still a major challenge.

Air-core inductors are another solution for VHF power supplies. They have the advantage of no core loss and high frequency operation [21]. Previous works reported on air-core inductors including 2D planar inductors [22], [23], onsubstrate 3D inductors [24], [25], and substrate-embedded 3D inductors [26], [27]. In many air-core inductors, the silicon substrate fully or partially remained, which causes undesired parasitic capacitance and eddy-current losses. Thus, quality factor and operating frequency are reduced [27]. Therefore, in the ideal air-core inductor design, the entire core must be removed.

Indeed, with the inductance of tens of $\mathrm{nH}$ [22], [26], [27], air-core inductors are suitable for VHF converters. Resonant converters allow the utilization of soft switching techniques due to the intrinsic alternating behavior of current, voltage or both by controlling the switches. Soft switching is desired to minimize the switching losses in the semiconductor devices [28]. High-performance gallium nitride field effect transistors (GaN FETs) have shown a great potential for high-voltage, VHF power supplies. GaN FETs have superior gate charge characteristics compared to other semiconductor transistors [29], [30]. The gate charge $\left(\mathrm{Q}_{\mathrm{G}}\right)$ multiplied by the onresistance $\left(\mathrm{R}_{\mathrm{DS} \text { ON }}\right)$ figure of merit shows that GaN FETs can be driven easily compared to their silicon counterparts. 
A DC-DC resonant converter consists of two stages which include an inverter stage and a rectifier stage. An inverter stage converts the DC input voltage to AC voltage or current, where after a rectifier stage converts $\mathrm{AC}$ current or voltage output of the inverter to a DC voltage or current. A common example of a rectifier stage is a class-D current-driven rectifier that was thoroughly studied and presented in [31], [32].

Inverter design is more challenging. Two examples of inverter topologies are class-E and class-D. The advantage of class-E inverter is that only one low side switch is needed to realize a power stage. However, they have a high voltage stress factor across the switch (drain-to-source voltage divided by the input voltage). This voltage stress can be 3.5 to 4 times higher than input supply voltage [33]-[37]. As a result, a high voltage switch with high breakdown voltage is required.

Class-D inverters on the contrary utilize two switches and have lower voltage stress on switches. The voltage stress equals to the input voltage which allows the usage of higher speed, lower voltage devices [36], [38]. To control two switches, precise design of the gate driver circuitry is needed to avoid cross conduction through the switches which may cause catastrophic failure. Other inverter topologies involve extra circuit components to solve the problem of high voltage stress on the switches [34], [36].

In this paper, a new silicon-embedded air-core toroidal inductor is presented. It has minimal parasitic capacitance and no substrate eddy-current losses due to a complete removal of silicon core. The miniaturized inductor is fabricated by an advanced 3D MEMS fabrication process, characterized by small-signal measurement, and demonstrated in a resonant power converter. The resonant boost converter is based on an agile Schottky-diode based class-D current-driven rectifier and a class-E inverter. The MEMS inductor is used in the resonant network, and a $65 \mathrm{~V}$ GaN FET is used as a switch. The converter is optimized to operate in zero voltage switching (ZVS) mode for minimal switching losses. Large signal highfrequency performance of the fabricated inductor is tested in terms of electrical and thermal performance, and $\mathrm{AC}$ current capability.

The paper is organized as follows. Section II presents the design and fabrication of the silicon-embedded air-core toroidal MEMS inductor. Section III describes small signal characterization of the MEMS inductor. IV presents design and simulation of a class-E boost converter. Converter performance is presented in Section $\mathrm{V}$, and conclusions follow in Section VI.

\section{INDUCTOR DESIGN AND FABRICATION}

\section{A. Inductor Design}

The proposed design of a MEMS air-core toroidal inductor is shown in Fig. 1. It is constructed with copper-filled through silicon vias (TSVs), suspended top and bottom windings, five silicon fixtures, and a silicon support die. The TSVs are positioned accordingly to toroidal shape with one TSV at the inner ring and two parallel TSVs at the outer ring. The number of fixtures is selected for mechanical stability of the suspended

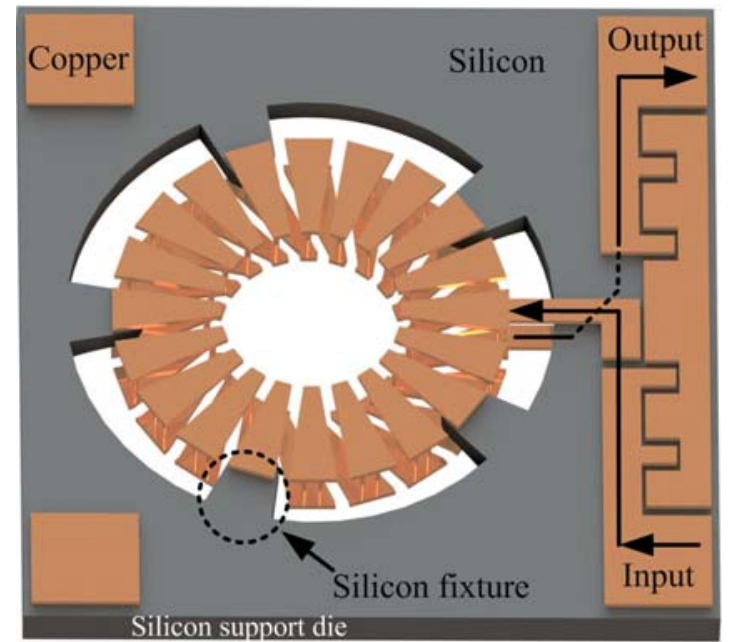

Fig. 1. 3D design of the MEMS air-core toroidal inductor with important features: copper-filled through-silicon vias (TSVs), suspending windings, silicon fixtures, silicon support die, pads for measurement and packaging, and ground-signal-ground probes for wafer-level characterization. The direction of inductor current is depicted by the arrows.

windings. The copper windings are attached to the silicon support die by silicon fixtures that cover outer TSVs and secure the suspended windings. The layout of input and output terminals includes ground-signal-ground pads for on-wafer measurement and two $800 \mu \mathrm{m} \times 800 \mu \mathrm{m}$ pads for connecting to PCB by wire bonding or flip-chip bonding. The direction of current flow is illustrated by the arrows in Fig. 1. The current flows from the input terminal through the windings, comes back to wafer backside, and gets out to the output terminal via through-silicon interconnects as shown by the arrows in Fig. 1.

This air-core design has four main advantages: low parasitic for high $\mathrm{Q}$ at high frequency, no substrate eddy-current losses due to a complete removal of silicon core, low electromagnetic interference (EMI) by using self-contained magnetic flux within the toroidal structure, and high compactness with the silicon-embedded construction.

\section{B. Fabrication Technology}

The MEMS inductor is fabricated by a novel 3D fabrication process. The process is developed based on MEMS fabrication technologies with the focus on complementary metal oxide semiconductor (CMOS) compatibility, scalability, and flexibility. The inductors can be fabricated with a wide range of geometry and sizes. The process consists of 12 steps and 4 photomasks. The details of fabrication process can be found in our fabrication paper [39]. In this paper, the fabrication process is summarized in four steps (Fig. 2a) as follows.

First, the TSVs are created by deep reactive ion etching (DRIE) (Fig. 2a). A 350- $\mu$ m-thick silicon wafer is etched through with holes $(50 \mu \mathrm{m}$ diameter) and narrow fixture trenches $(3 \mu \mathrm{m}$ and $7 \mu \mathrm{m}$ width) which are defined by photolithography. The holes are etched through, while the trenches are not. By the end of step 1, hollow silicon TSVs are created. Second, copper is deposited as the conductive material (Fig. 2b). After depositing insulation layers including aluminum oxide $\left(\mathrm{Al}_{2} \mathrm{O}_{3}\right)$ and silicon dioxide $\left(\mathrm{SiO}_{2}\right)$, copper is electroplated into the TSVs and on both wafer sides. The 


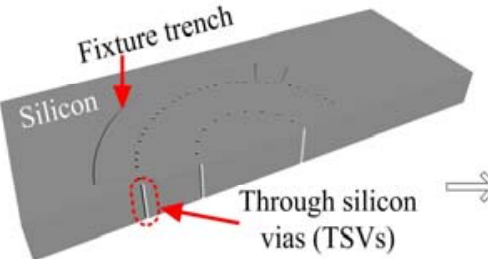

Step 1: Through-silicon etching

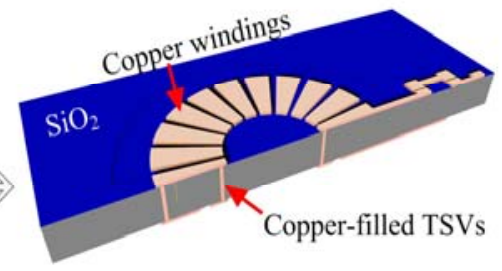

Step 2: Copper electroplating

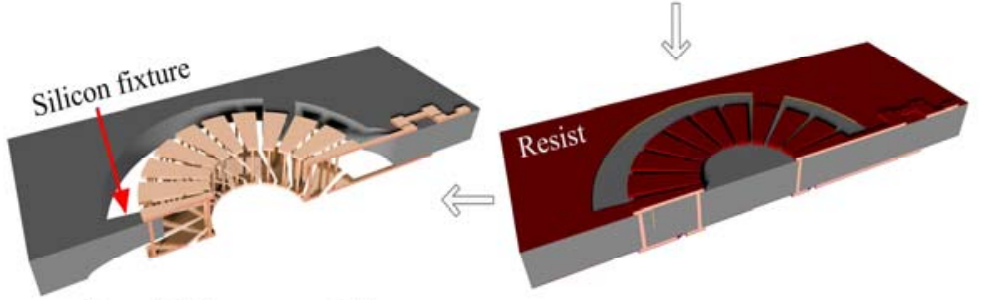

Step 4: Silicon core etching

Step 3: Lithography + wet etching

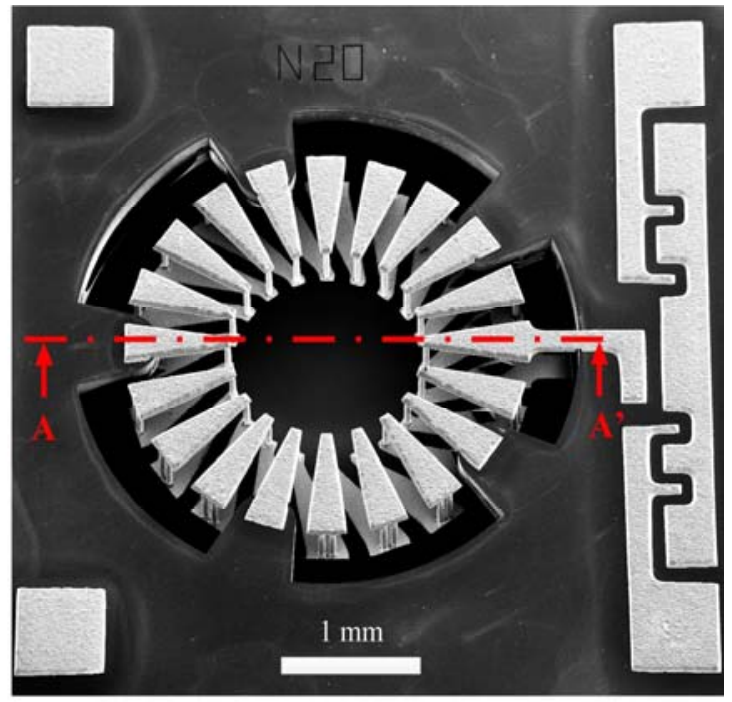

Fig. 2. (a) A four-step fabrication process of MEMS air-core toroidal inductor viewed from direction A-A'. Step 1 is to create 50 - $\mu$ m-diameter through-silicon vias (TSVs) in a 350- $\mu \mathrm{m}$-thick wafer by deep reactive ion etching and atomic layer deposition. Step 2 includes deposition of insulation layers 50 nm aluminum oxide (A12O3) and $1.5 \mu \mathrm{m}$ silicon dioxide ( $\mathrm{SiO} 2)$, electroplating of copper in TSVs and top and bottom conductors, and copper wet etching to define the toroidal windings. Step 3 starts with protecting copper windings by aluminum oxide followed by photolithography of spray-coated resist and wet etching using hydrofluoric acid. Step 4 is to etch the silicon core using dry ICP etching and release the suspended windings by wet etching and drying steps. (b) A secondary electron microscopy (SEM) micrograph of MEMS air-core inductor with $1.5 \mathrm{~mm}$ outer diameter, $0.75 \mathrm{~mm}$ inner diameter, 20 turns, $350 \mu \mathrm{m}$ height, and $50 \mu \mathrm{m}$ TSV diameter. The thickness of top and bottom windings is $50 \mu \mathrm{m}$. Winding gap is $94 \mu \mathrm{m}$.

aluminum oxide $\left(\mathrm{Al}_{2} \mathrm{O}_{3}\right)$ is deposited by atomic layer deposition (ALD) using a process developed for depositing $\mathrm{Al}_{2} \mathrm{O}_{3}$ on high-aspect-ratio structures [40]. Third, an etching mask is created prior to removal of the silicon core. A $50 \mathrm{~nm}$ layer of $\mathrm{ALD} \mathrm{Al}_{2} \mathrm{O}_{3}$ is deposited. Photoresist ( $\mathrm{AZ} 4562$, Microchem., USA) is then spray-coated followed by photolithography. It is crucial for the resist to fill and seal the fixture trenches prior to the next $\mathrm{Al}_{2} \mathrm{O}_{3}$ wet etching step using buffered hydrofluoric acid (BHF). Last, the silicon core is removed using isotropic dry etching by an inductively coupled plasma (ICP) silicon etching tool followed by releasing steps including $\mathrm{BHF}$ wet etching, deionized water rinsing, and nitrogen drying. By utilizing $\mathrm{Al}_{2} \mathrm{O}_{3}$ deposited on the fixture trenches as an etch stop, the silicon core can be removed completely without damaging silicon fixtures. The fixture trenches define the silicon fixtures and support die, thus defining the toroidal core. The process temperature is kept below $200{ }^{\circ} \mathrm{C}$, and this enables post MEMS processing on CMOS wafers and avoid damaging the existing active electronics.

The fabricated MEMS air-core toroidal inductor is shown in Fig. 2. It has 20 turns, $350-\mu \mathrm{m}$-tall, and the footprint is $9 \mathrm{~mm}^{2}$. The silicon core was removed completely while the silicon fixtures and support die remained undamaged. No winding deformation was observed after the releasing steps.

The fabrication process has the advantages of fabricating inductors with a wide range of sizes and shapes. A process yield of $95 \%$ was achieved. Magnetic composite core inductors can also be made using the fabricated TSV air-core inductors and a simple screen-printing process. One limitation of the process is a large winding gap of $94 \mu \mathrm{m}$ due to the $\mathrm{Cu}$ wet-etching step. This can be improved by a minor modification in step 2 of the process. For example photoresist is used as a mold for electroplating of $\mathrm{Cu}$.

The thermal and mechanical stability of the fabricated inductors were tested with a thermal cycling test $(250$ cycles, 45 to $155^{\circ} \mathrm{C}$ ) and a drop test up to $2 \mathrm{~m}$, respectively. The results are also presented in our fabrication paper [39]. The inductors with the turn/fixture ratio from 6 (30 turns:5 fixtures) to 10 (30 turns:3 fixtures) were tested. They showed good stability after the tests. The suspended windings did not deform and the inductors were still functional. If a higher robustness is required, the air core inductor can be filled with epoxy for stability enhancement.

\section{SMALl SignAl CHARACTERIZATION OF INDUCTOR}

Air-core and silicon-core MEMS inductors were electrically characterized from 0.9 to $110 \mathrm{MHz}$ using a precision impedance analyzer (Agilent 4294A). A dedicated PCB (Fig. $3 a$ ) is used as the interface to test the MEMS inductors. An inductor is mounted on the test board using epoxy which is cured at $220{ }^{\circ} \mathrm{C}$ for 30 minutes using a convection oven. The inductor input and output terminals are connected to the test board through three $30-\mu \mathrm{m}$-diameter gold wires. Impedance analyzer calibration is done with short connection, open connection, and $50 \Omega$. The calibration boards are shown in Fig. 3b. Short connection is made by three parallel gold wires. Inductance $(\mathrm{L})$, quality factor $(\mathrm{Q})$, and $\mathrm{AC}$ resistance $\left(\mathrm{R}_{\mathrm{AC}}\right)$ are measured (Fig. 3c, d).

The air-core inductor has an inductance of $44.6 \mathrm{nH}, \mathrm{Q}_{\text {peak }}$ of 13.3 at 33.2 MHz. The silicon-core $(\rho=1-20 \Omega \mathrm{cm})$ inductor has an inductance of $43.7 \mathrm{nH}$ and lower $Q_{\text {peak }}$ of 9 at lower frequency of $20 \mathrm{MHz}$. The optimal operating frequency of the air-core inductor to be used in the converter is at $33 \mathrm{MHz}$. At $33 \mathrm{MHz}$, the AC resistance $\left(\mathrm{R}_{\mathrm{AC}}\right)$ of the air-core inductor is $0.65 \Omega$ which is two times lower compared to $1.25 \Omega$ of the 


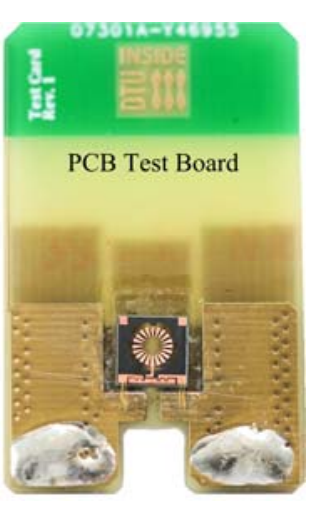

(a)
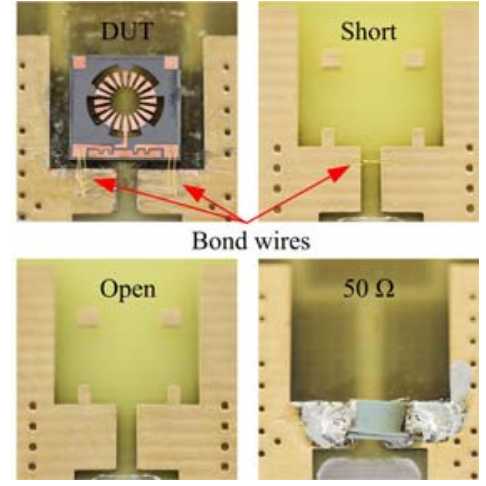

(b)

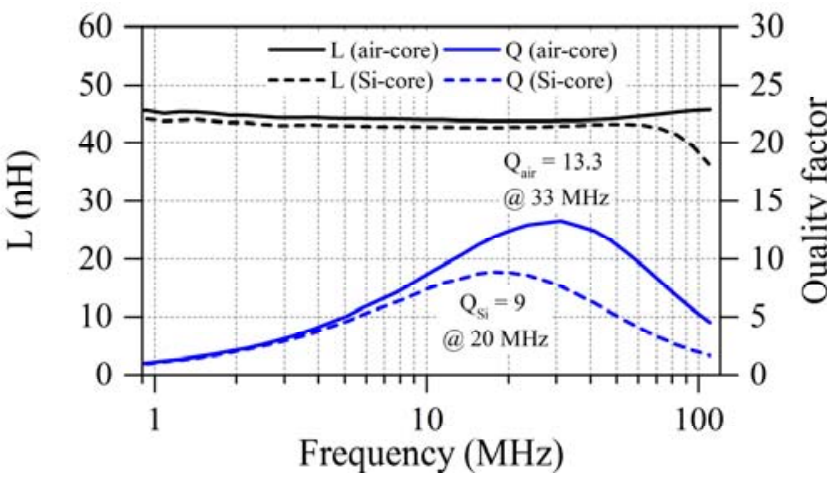

(c)

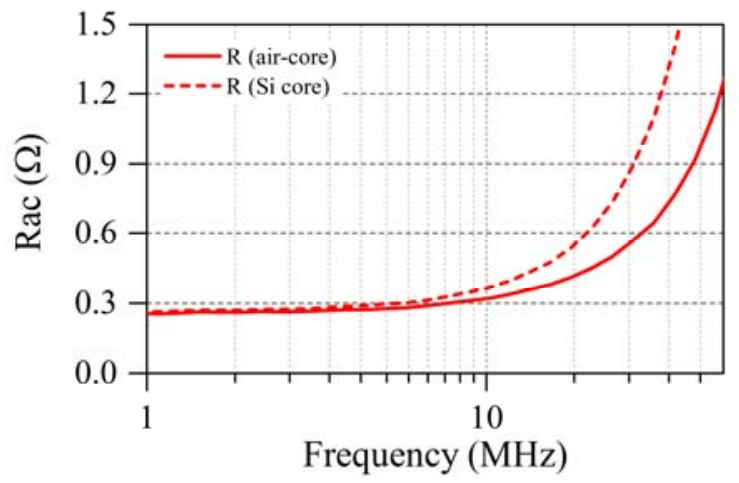

(d)

Fig. 3. Small signal characterization of air-core and silicon-core toroidal inductors. (a) PCB test board. An air-core inductor is glue-mounted and connected to the test board through three parallel gold wires. (b) A device under test (DUT) and calibration structures including short connection, open connection, and $50 \Omega$. (c) Measured inductance (L) and quality factor (Q) in the frequency range from $0.9 \mathrm{MHz}$ to $110 \mathrm{MHz}$. (d) Measured AC resistance $\left(\mathrm{R}_{\mathrm{AC}}\right)$ in the frequency range from $0.9 \mathrm{MHz}$ to $50 \mathrm{MHz}$. Air-core and siliconcore inductors have inductance of $44.6 \mathrm{nH}$ and $43.7 \mathrm{nH}$. Air-core inductor is better than silicon-core inductor with higher Qpeak of 13.3 at higher frequency of $33 \mathrm{MHz}$.

silicon-core inductor. The increase in resistance results in a lower Q factor in the Si-core inductors. This is due to a higher parasitic capacitance and the substrate eddy-current loss of the Si-core inductor. The measured results showed a three-fold higher parasitic capacitance in the Si-core inductor with 11.5 $\mathrm{pF}$ compared to $3.7 \mathrm{pF}$ of the air-core inductor, thus allowing the air-core inductor to operate at higher frequency with higher Q factor. This paper focuses on the characterization and demonstration of the fabricated air-core inductors, and the

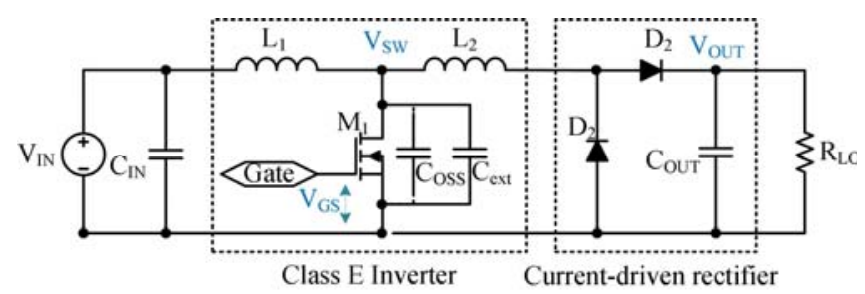

(a)

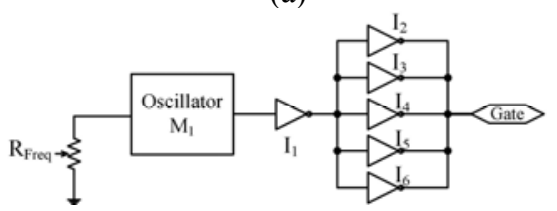

(b)

Fig. 4. Circuit diagram of (a) Class E resonant boost converter includes a Class E inverter and a Schottky-diode based class D current driven rectifier. The converter is optimized for zero voltage switching at $33 \mathrm{MHz}$. (b) frequency-tunable gate driver using silicon oscillator and variable resistor with fixed $50 \%$ duty cycle.

models of the air-core toroidal inductors can be found in [41][43].

\section{Class-E Resonant BoOst CONVERTER}

\section{A. Converter Design}

To test the inductor, a class-E resonant boost converter has been selected. The converter is designed to operate in ZVS mode at $33 \mathrm{MHz}$ where the inductor has a maximum $\mathrm{Q}$ of 13.3, $\mathrm{R}_{\mathrm{AC}}$ of $0.65 \Omega$, and $\mathrm{L}$ of $44.6 \mathrm{nH}$. Fig. 4a shows the topology of the resonant converter. The converter consists of two parts: rectifier and inverter.

The first part is a class-D current driven rectifier [31], [32] which is used to drive the load resistance. The rectifier allows DC power flow through $\mathrm{D}_{2}$ to the load and $\mathrm{AC}$ power flow through rectification act. A similar concept was reported in [28] where a resonant type rectifier was used instead of class$\mathrm{D}$ in this case. A reported resonant rectifier [28] is not used in this converter to reduce the amplitude of high frequency current flowing in the inductor under test. This will prevent extra AC losses in the inductor. It is beneficial to deal with $\mathrm{D}_{1}$ as a freewheeling diode when $\mathrm{L}_{2}$ current becomes negative.

The second part is the inverter which consists of an input choke $\left(\mathrm{L}_{1}\right)$, a GaN FET $\left(\mathrm{M}_{1}\right)$, a capacitor $\left(\mathrm{C}_{\text {ext }}\right)$ and finally the inductor under test $\left(\mathrm{L}_{2}\right)$. The GaN FET is driven by a logic buffer with an output stage of five inverters connected in parallel as shown in Fig. 4b. The frequency is set by a silicon oscillator with a fixed duty cycle of $50 \%$. $\mathrm{L}_{2}$ is used as a part of the resonant network, and it also delivers DC current to the load. $\mathrm{L}_{1}$ has a high inductance and it is mainly carrying DC current so, the AC losses are minimal.

The working principle of the proposed converter is described by analyzing the steady-state waveforms of switching node voltage $\left(\mathrm{V}_{\mathrm{Sw}}\right)$, gate voltage $\left(\mathrm{V}_{\mathrm{GS}}\right)$, and inductor under test current $\left(\mathrm{I}_{\mathrm{L} 2}\right)$. It is assumed that the converter perfectly operates in ZVS mode, i.e. the charge stored in the equivalent output capacitance $\left(\mathrm{C}_{\text {eqv }}\right)$ of $\mathrm{M}_{1}$ is fully discharged before the FET turns on. One switching cycle can be divided into five-time sub-intervals or states as 


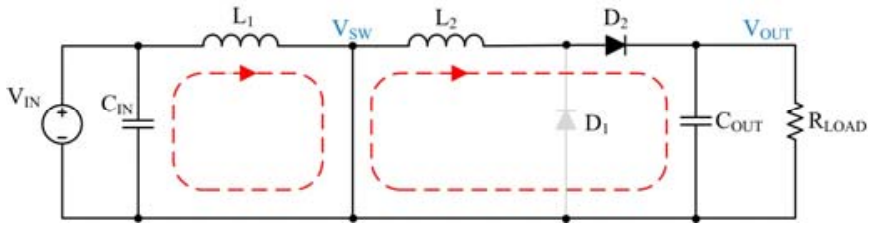

(a) State 1: $\mathrm{M}_{1} \mathrm{ON}, \mathrm{D}_{1} \mathrm{OFF}, \mathrm{D}_{2} \mathrm{ON}$

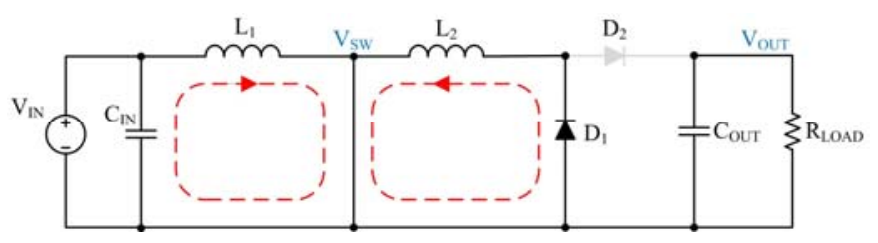

(b) State 2: $\mathrm{M}_{1} \mathrm{ON}, \mathrm{D}_{1} \mathrm{ON}, \mathrm{D}_{2} \mathrm{OFF}$

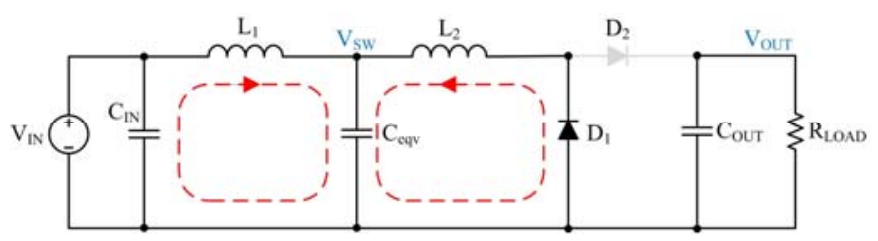

(c) State 3: $\mathrm{M}_{1} \mathrm{OFF}, \mathrm{D}_{1} \mathrm{ON}, \mathrm{D}_{2} \mathrm{OFF}$

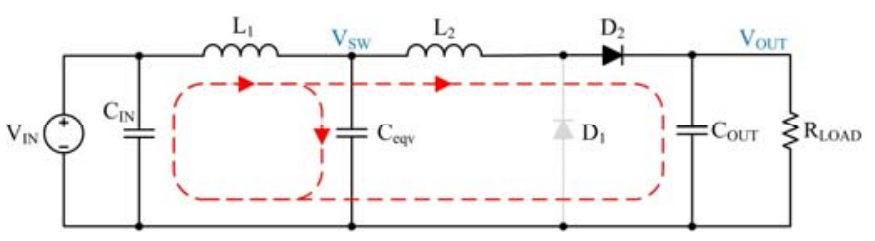

(d) State 4: $\mathrm{M}_{1}$ OFF, $\mathrm{D}_{1} \mathrm{OFF}, \mathrm{D}_{2} \mathrm{ON}$

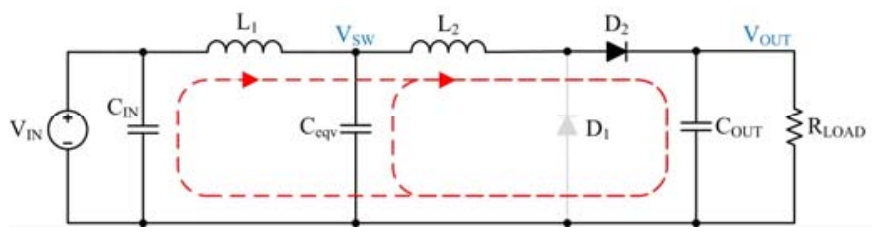

(e) State 5: $\mathrm{M}_{1}$ OFF, $\mathrm{D}_{1}$ OFF, $\mathrm{D}_{2} \mathrm{ON}$

Fig. 5. Working principle of a Class E resonant boost converter is described by analyzing five states of GaN FET $\left(M_{1}\right)$, Schottky diodes $D_{1}$, and $D_{2}$ corresponding to five time intervals of one switching cycle.as shown " $"$ in Fig. 6 . The fade color represents the off state of the device.

illustrated in Fig. 5 and Fig. 6.

State 1: the GaN FET $\mathrm{M}_{1}$ is turned on by the gate driver. $\mathrm{L}_{1}$ is charged linearly from $V_{\text {IN. }} L_{2}$ is discharges through $D_{2}$ and delivers energy to the load until $\mathrm{I}_{\mathrm{L} 2}=0$. In ideal operation condition, it is required to switch M1 on when the drain to source voltage is $0 \mathrm{~V}$ to achieve soft switching.

State 2: the equivalent capacitance of $\mathrm{D}_{1}$ is discharged through $\mathrm{L}_{2}$. $\mathrm{I}_{\mathrm{L} 2}$ changes direction making $\mathrm{D}_{2}$ reverse biased and $\mathrm{D}_{1}$ forward biased. $\mathrm{L}_{1}$ is still being charged by $\mathrm{V}_{\mathrm{IN}}$. During this interval, the current flowing in the GaN FET M1 is the summation of $\mathrm{I}_{\mathrm{L} 1}$ and $\mathrm{I}_{\mathrm{L} 2}$ Fig. 5 .

State 3: $\mathrm{M}_{1}$ is turned off by the gate driver. $\mathrm{L}_{2}$ continue

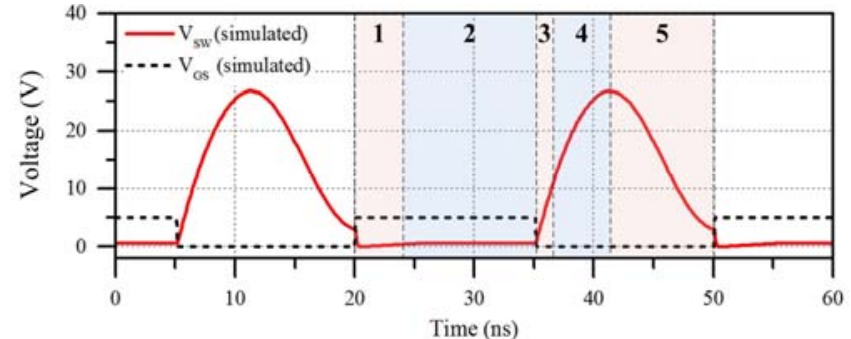

(a)

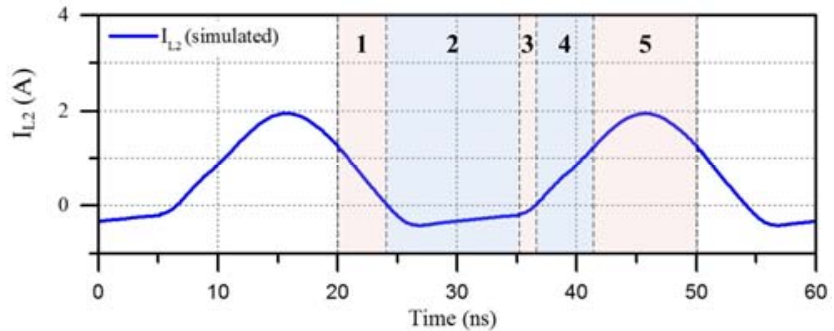

(b)

Fig. 6. Simulated waveforms of (a) Voltage at switching node $\left(\mathrm{V}_{\mathrm{SW}}\right)$ and gate voltage $\left(\mathrm{V}_{\mathrm{GS}}\right),(\mathrm{b})$ inductor under test current $\left(\mathrm{I}_{\mathrm{L} 2}\right)$ as function of time from 0 to $60 \mathrm{~ns}$ i.e. 2 switching cycles at $33 \mathrm{MHz}$. A fixed load is set to be $20 \Omega$. One cycle is divided into five time intervals corresponding to five operation states of $\mathrm{M}_{1}, \mathrm{D}_{1}$, and $\mathrm{D}_{2}$.

discharging through $\mathrm{D}_{1}$ and charging the equivalent output capacitance for the GaN FET $\left(\mathrm{C}_{\text {eqv }}\right)$. $\mathrm{C}_{\text {eqv }}$ is a combination of the GaN FET output capacitance and an external ceramic capacitor in the circuit $\left(\mathrm{C}_{\mathrm{ext}}\right)$. As a result, the switching node voltage $\left(\mathrm{V}_{\mathrm{SW}}\right)$ is rising. By the end of interval $3, \mathrm{~L}_{2}$ is fully discharged $\left(\mathrm{I}_{\mathrm{L} 2}=0\right)$ and $\mathrm{I}_{\mathrm{L} 1}$ reaches its peak current.

State 4: $D_{2}$ is forward biased while $D_{1}$ is reverse biased. A part of the stored charge in $L_{1}$ is used to charge $C_{\text {eqv }}$ so, $V_{S W}$ keeps increasing. Some energy is also transferred to the load through $\mathrm{L}_{2}$ which is charging in the same time. By the end of interval $4, \mathrm{C}_{\text {eqv }}$ is fully charged and $\mathrm{V}_{\mathrm{SW}}$ reaches a maximum voltage.

State 5: $D_{1}$ is off and $D_{2}$ is forward biased. $C_{\text {eqv }}$ starts to discharge and its current combined with $\mathrm{I}_{\mathrm{L} 1}$ flows to the load. $\mathrm{L}_{2}$ keep charging until $\mathrm{I}_{\mathrm{L} 2}$ reaches its peak value when $\mathrm{V}_{\mathrm{SW}}$ equals $V_{\text {OUT. }} \mathrm{L}_{2}$ then discharges through $\mathrm{D}_{2}$ to the load until $\mathrm{I}_{\mathrm{L} 2}$ equals $\mathrm{I}_{\mathrm{L} 1}\left(\mathrm{C}_{\mathrm{eqv}}\right.$ is fully discharged).

\section{B. Simulation}

The proposed converter topology is simulated in LT-Spice. The input voltage $\left(\mathrm{V}_{\mathrm{IN}}\right)$ is set to be $8.4 \mathrm{~V}_{\mathrm{DC}}$ with a fixed $20 \Omega$ load. The simulated waveforms of the switching node $\left(\mathrm{V}_{\mathrm{SW}}\right)$, GaN FET gate-to-source voltage $\left(\mathrm{V}_{\mathrm{GS}}\right)$, and the inductor current $\left(\mathrm{I}_{\mathrm{L} 2}\right)$ are shown in Fig. 6 . The switching frequency was chosen to be $33 \mathrm{MHz}$ to match the peak quality factor of the MEMS air-core inductor. $\mathrm{V}_{\mathrm{SW}}$ waveform indicates that the converter is operating close to ZVS mode. $\mathrm{C}_{\text {eqv }}$ is tuned externally to achieve ZVS operation since $\mathrm{L}_{2}$ is fixed at $45 \mathrm{nH}$. A $180-\mathrm{pF}$ external capacitor $\left(\mathrm{C}_{\mathrm{ext}}\right)$ was optimized to achieve soft switching operation at $33 \mathrm{MHz}$. The choke inductor $\mathrm{L}_{1}$ is set to a high inductance value as it is assumed to carry DC current with a small AC ripple. $\mathrm{L}_{1}$ is chosen to be $1 \mu \mathrm{H}$. From the waveform of $\mathrm{I}_{\mathrm{L} 2}$, the root mean square (RMS) inductor current is around $1 \mathrm{~A}$ with an average of $0.56 \mathrm{~A} \mathrm{DC}$. The 


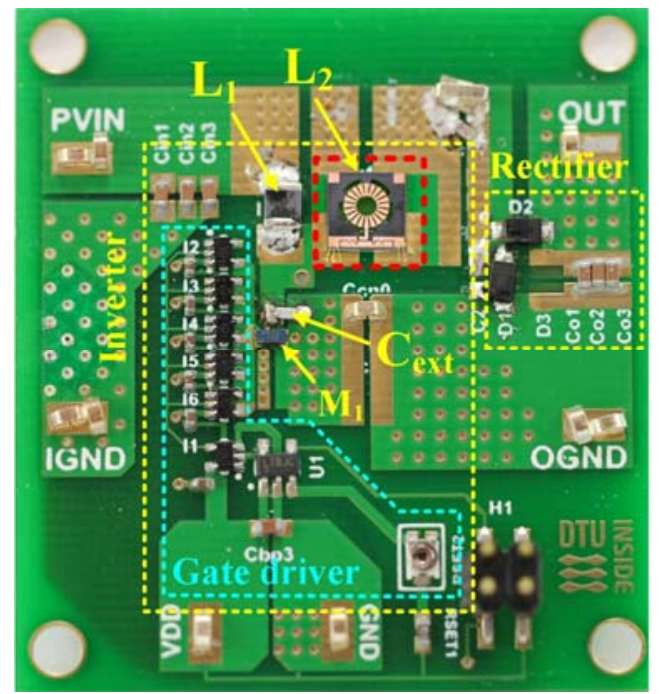

(a)

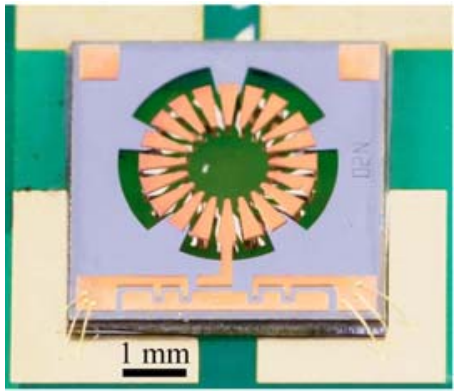

(b)

Fig. 7. (a) Optical image of the converter. (b) A close-up images of an air-core toroidal inductor which is mounted onto PCB by cured epoxy glue. Electrical connections are made by three 30 - $\mu \mathrm{m}$-diameter gold wires bonded in parallel. simulated voltage conversion ratio $\left(\mathrm{V}_{\mathrm{OUT}} / \mathrm{V}_{\mathrm{IN}}\right)$ is 1.56 .

\section{EXPERIMENTAL RESULTS AND DISCUSSIONS}

The proposed converter is implemented on a $4 \mathrm{~cm} \mathrm{x} 4 \mathrm{~cm}$ PCB (Fig. 7). There are two main blocks corresponding to an inverter and a rectifier (Fig. 7a). A gate driver with tunable silicon oscillator is in the first inverter block. The gate driver is powered by a $5 \mathrm{~V}$ external voltage source. Based on simulation results, all components are selected as presented in Table I. A MEMS air-core inductor is mounted using epoxy and connected to the PCB using gold wire bonding. A magnified view of $L_{2}$ is shown in Fig. 7b. Here, the integration of $\mathrm{L}_{2}$ is the prime interest because it is used as an energystorage element in the resonant network. $\mathrm{L}_{2}$ carries a highfrequency $\mathrm{AC}$ current, it is therefore challenging to integrate due to the excess core loss. On the other hand, $\mathrm{L}_{1}$ is a $1-\mu \mathrm{H}$ choke inductor that is used to block the $\mathrm{AC}$ current and only carries DC current. The integration of such inductors is less challenging because the unwanted high-frequency effects e.g. eddy currents, core loss, and EMI are not crucial. This allows the use of low-frequency, high-permeability magnetic materials e.g. permalloy ( $\mathrm{NiFe}$ ) and supemalloy (NiFeMo).

The measurement results are shown in Fig. 8 with the measured waveforms of gate and drain voltages. A close operation to ZVS can be observed in Fig. 8 from the
TABLE I

COMPONENT SELECTION

\begin{tabular}{lll}
\hline \hline Symbol & \multicolumn{1}{c}{ Part number } & \multicolumn{1}{c}{ Description } \\
\hline $\mathrm{L}_{2}$ & - & $44.6 \mathrm{nH}$, air-core toroidal inductor \\
$\mathrm{M}_{1}$ & EPC8002 & $65 \mathrm{~V} \mathrm{GaN} \mathrm{FET}$ \\
$\mathrm{L}_{1}$ & LQM32PN1R0MG0L & $1 \mu \mathrm{H}, 1.8 \mathrm{~A}$, Multilayer inductor \\
$\mathrm{D}_{1}, \mathrm{D}_{2}$ & PMEG4010BEA & $40 \mathrm{~V}, 1 \mathrm{~A}$, Schottky diode \\
$\mathrm{C}_{\mathrm{IN}}$ & GRT188R61H225KE13D & $2.2 \mu \mathrm{F}, 50 \mathrm{~V}, \mathrm{X}$ R $($ quantity $=3)$ \\
$\mathrm{CouT}$ & GRT188R61H225KE13D & $2.2 \mu \mathrm{F}, 50 \mathrm{~V}, \mathrm{X}$ R $($ quantity $=3)$ \\
$\mathrm{I}<1: 6>$ & 74LVC1GU04GW-Q100H & Logic inverter chip (quantity $=6)$ \\
$\mathrm{M} 1$ & LTC6905CS5 & Tunable silicon oscillator \\
$\mathrm{C}_{\text {ext }}$ & GRM1885C1H181JA01D & $180 \mathrm{pF}$ ceramic capacitor \\
\hline \hline
\end{tabular}

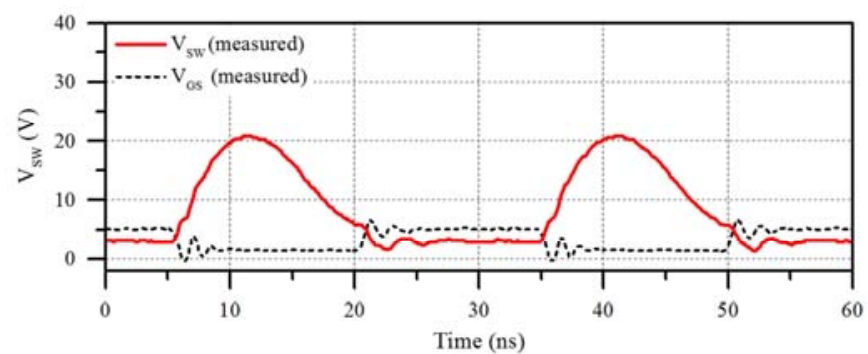

Fig. 8. Measured waveforms. (a) Voltage at switching node ( $\left.\mathrm{V}_{\mathrm{sw}}\right)$, (b) Gate voltage $\left(\mathrm{V}_{\mathrm{GS}}\right)$

waveform of $V_{S W}$ when $V_{S W}$ returns to zero before $M_{1}$ is turning on. Fig. 9 shows the measured efficiency $(\eta)$, power loss $\left(\mathrm{P}_{\text {LOSS }}\right)$, output voltage $\left(\mathrm{V}_{\text {OUT }}\right)$, and output power ( $\left.\mathrm{P}_{\text {OUT }}\right)$ of the converter with a sweep of input voltage $\left(\mathrm{V}_{\mathrm{IN}}\right)$ from $3 \mathrm{~V}$ to $10 \mathrm{~V}$. The average conversion ratio $\left(\mathrm{V}_{\text {OUT }} / \mathrm{V}_{\mathrm{IN}}\right)$ is 1.48 . The efficiency without gate driver loss ( $\eta_{\text {WO_GD }}$ ) increases from $73.4 \%$ to $77.3 \%$ with $\mathrm{V}_{\text {IN }}$ from $3 \mathrm{~V}$ to $10 \mathrm{~V}$, and then saturates with an efficiency of about $77 \%$. The converter achieved a peak efficiency of $77.3 \%$ at an input voltage $\mathrm{V}_{\text {IN }}=$ $6.5 \mathrm{~V}$ with an output voltage of $\mathrm{V}_{\text {OUT }} 9.7 \mathrm{~V}$ and an output power level of $\mathrm{P}_{\text {OUT }}=6.1 \mathrm{~W}$. The total power loss $\mathrm{P}_{\mathrm{D}}$ is 1.5 $\mathrm{W}$. The converter can delivery up to $14.5 \mathrm{~V}_{\mathrm{OUT}}$ and $10.5 \mathrm{~W}$ Pout. At the target switching frequency of $33 \mathrm{MHz}$, the gate driver loss is $0.15 \mathrm{~W}$. The efficiency including the gate driver loss and the oscillator ( $\eta_{\mathrm{W}_{-} \mathrm{GD}}$ ) is $75.5 \%$. For testing purposes, the gate driver is built externally, but the gate driver loss can be reduced by proper design of the gate driver with an integrated circuit process.

The MEMS inductor AC power loss was estimated via DC power loss using thermal measurement method. The idea is to drive an increasing DC current through the inductor until its thermal image is matched with its thermal image during $\mathrm{AC}$ converter operation. The DC power loss is obtained by multiplying the inductor voltage by the applied DC current. Fig. $10 \mathrm{~b}$ and $\mathrm{c}$ show a matching of inductor temperature for the AC and DC power loss, respectively. A DC current of 1.53 A was measured with a $0.646 \mathrm{~V}$ DC voltage. The DC power loss is then calculated to be $0.98 \mathrm{~W}$ which equals to the $\mathrm{AC}$ power loss. In addition, the high-temperature DC resistance of the inductor is measured to be $0.42 \Omega$.

Fig. 10 shows thermal images of the converter with $8.4 \mathrm{~V}$ $\mathrm{V}_{\text {IN }}$. The GaN FET temperature is $77.4{ }^{\circ} \mathrm{C}$. Because of $\mathrm{Cu}$ reflects in the thermal image, an absolute thermal measurement of $\mathrm{Cu}$ is not possible, and the copper windings 


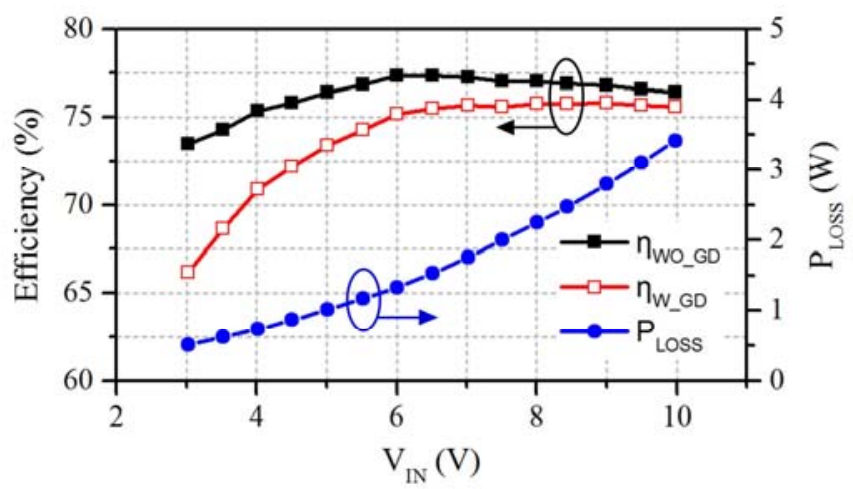

(a)

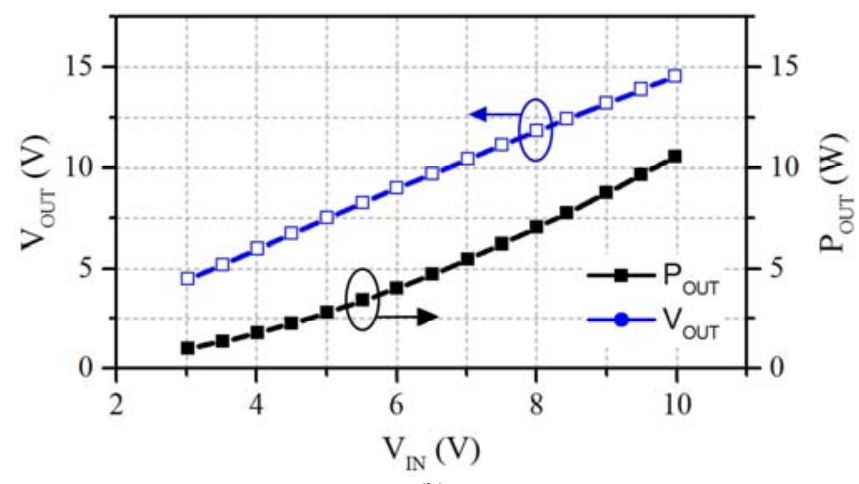

(b)

Fig. 9. Characterization results of boost converter using a microfabricated aircore inductor. (a) Efficiency of the converter without loss in gate driver $\left(\eta_{\text {wo GD }}\right)$, with loss in gate driver $\left(\eta_{\text {wo GD }}\right)$, and total power loss $\left(P_{\text {LOSS }}\right)$ including gate driver loss of $0.15 \mathrm{~W}$ versus input voltage $\left(\mathrm{V}_{\mathrm{IN}}\right)$. (b) Output power (PouT) and output voltage (VOUT) versus VIN.

temperature can be estimated by matching the measured DC resistance at room temperature to the $\mathrm{DC}$ resistance measured at high temperature. The details of DC resistance measurement at room temperature and the method to estimate the absolute $\mathrm{Cu}$ temperature are presented in the Appendix. The temperature of the copper windings is calculated to $108{ }^{\circ} \mathrm{C}$ which is slightly above the temperature of the silicon die in Fig. 10b. The thermal performance of the air-core inductor can be improved by implementing a thermal pad underneath the inductor.

For better performance, the toroidal windings can be further optimized to achieve a lower resistance and a higher inductance density which will result in smaller inductors. The improvements can be made on the TSV design, e.g. increasing the diameter and the density of the circular TSVs will result in a lower resistance. Alternatively, using a single rectangular outer TSV will also increase winding coverage and lead to a lower resistance. Parallel inner TSVs will have a significant improvement in the resistance, but the effective toroidal-core volume will reduce. This can be done with a two-step deep reactive ion etching (DRIE) and electrodeposition process. A simple process modification can increase the winding thickness and density: using mold-based electrodeposition as a replacement for copper wet-etching. Mold-base technology was reported in [44] for a racetrack inductor, which has a copper thickness of $85 \mu \mathrm{m}$ and a winding gap of $5 \mu \mathrm{m}$.

The heat-dissipation performance of the air-core and Si-core

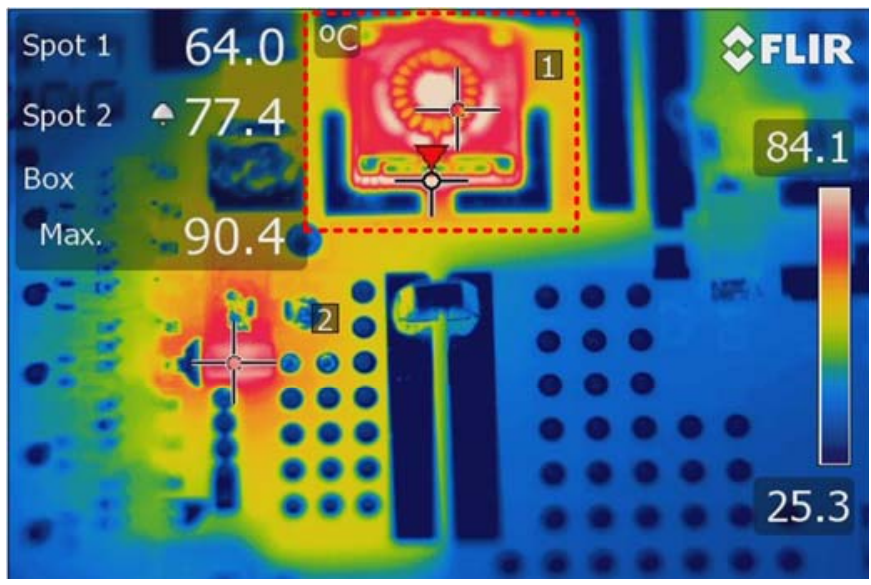

(a)

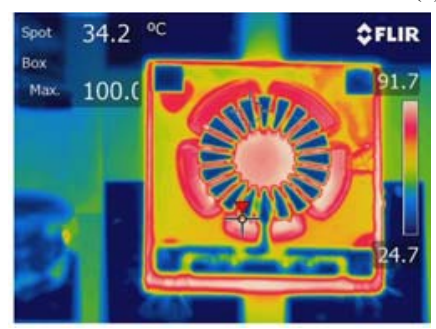

(b)

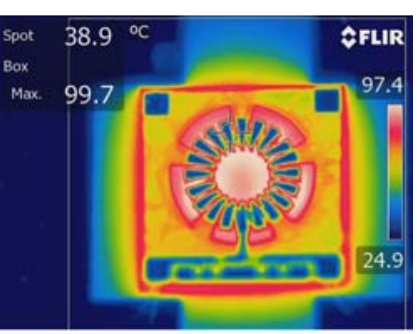

(c)
Fig. 10. (a) Thermal images of converter with $\mathrm{V}_{\mathrm{IN}}=8.4 \mathrm{~V}$ captured by FLIR camera T600 (FLIR, USA) using standard lens. Close-up thermal images of the microfabricated inductor for two cases: (b) large signal performance with AC current from the converter and (c) DC current testing with an equivalent thermal performance. DC power loss in the inductor is $0.98 \mathrm{~W}$ with $1.53 \mathrm{~A} \mathrm{DC}$ current and $0.646 \mathrm{~V}$. The close-up images were captured by a FLIR close-up IR 2.9x lens with $50 \mu \mathrm{m}$ detector pitch. The measurement condition is with airflow and without thermal pad for cooling down underneath the die. There is signal reflected from the board which induces biases to the measured temperature.

inductors was compared in our fabrication paper [39]. The efficiency is $64 \%$ with the Si-core inductor and $68 \%$ with the air-core inductor with $30{ }^{\circ} \mathrm{C}$ higher than that of the air-core inductor. Indeed, the $\mathrm{Si}$ core has a much higher thermal conductivity for heat dissipation, but with the same windings, the air-core inductor has lower resistance compared to that of the Si-core due to: capacitive coupling and the eddy-current loss in the Si substrate. At $33 \mathrm{MHz}$, the Si-core inductor has a resistance of $1.25 \Omega$ compared to $0.65 \Omega$ of the air-core inductor. To further improve heat dissipation, the MEMS aircore inductor can be filled with thermal epoxy, which has a better thermal conductivity and extremely high resistivity. E.g. EPO-TEK ${ }^{\circledR}$ 921-FL (Epotek, USA) which has $\mathrm{k}=1.1 \mathrm{~W} / \mathrm{mK}$, and $\rho>6.10^{13} \Omega \mathrm{cm}$. We developed a screen-printing process and demonstrated an implementation of a magnetic composite core using epoxy and NiZn powders [45]. This process can also be used for making a thermal-epoxy core inductor.

\section{CONCLUSION}

A study on silicon-embedded air-core toroidal MEMS inductor for PwrSoC applications has been presented. The proposed microfabrication process enables fabrication of $3 \mathrm{D}$ MEMS toroidal inductor with a unique air-core design. The inductors are embedded in a silicon substrate with through- 
silicon vias and suspended copper windings. The silicon-core has been removed completely to increase the quality factor and operating frequency. Air-core and silicon-core inductors were electrically characterized and compared. The results imply that the air-core inductors are better for very high frequency operation with higher quality factor at higher frequency. The MEMS air-core inductor has a quality factor of 13.3 at $33 \mathrm{MHz}$ while a silicon-core inductor has a quality factor of 9 at $20 \mathrm{MHz}$. A VHF class-E boost converter was designed and optimized for zero voltage switching using the MEMS inductor and a GaN FET. The testing results showed that the inductor can handle an RMS current of $1 \mathrm{~A}$ and deliver a maximum power of $10.5 \mathrm{~W}$ to the output with a peak efficiency of $77.3 \%$. Based on our results that laid the cornerstone of MEMS inductor applications in power converters, we believe that MEMS inductors will play an important role for the development and realization of the PwrSoC vision.

\section{APPENDIX}

The absolute temperature of the copper windings (T) can be estimated by a linear approximation (1) [46].

$$
T=\frac{R_{T} / R_{0}-1}{\alpha_{C u}}+T_{0}
$$

where $\alpha_{C u}=4.29(\mathrm{ppm} / \mathrm{K})$ is the temperature coefficient of copper. $\mathrm{T}_{0}$ is room temperature of $22{ }^{\circ} \mathrm{C} . \mathrm{R}_{\mathrm{T}}$ is the $\mathrm{DC}$ resistance measured at $\mathrm{T}^{\circ} \mathrm{C}$ which equals to $0.42 \Omega$. $\mathrm{R}_{0}$ is the $\mathrm{DC}$ resistance measured at room temperature. $\mathrm{R}_{0}$ At room temperature, the DC resistance $\left(\mathrm{R}_{0}\right)$ is re-measured precisely by applying a small DC current and measure the voltage across the inductor. An average $R_{0}$ of $0.308 \Omega$ is measured including gold wires and PCB parasitic. The details of DC resistance measurement are presented in Table II. The absolute temperature of the copper windings $(\mathrm{T})$ is calculated to be 108 ${ }^{\circ} \mathrm{C}$.

TABLE II

MEASUREMENT OF DC RESISTANCE INCLUDING GOLD WIRES AND PCB PARASITICS AT ROOM TEMPERATURE

\begin{tabular}{ccc}
\hline \hline $\begin{array}{c}\text { Applied DC current } \\
(\mathrm{mA})\end{array}$ & $\begin{array}{c}\text { Measured voltage } \\
(\mathrm{mV})\end{array}$ & $\begin{array}{c}\text { DC Resistance } \\
(\Omega)\end{array}$ \\
\hline 10.37 & 3.2 & 0.309 \\
20.33 & 6.24 & 0.307 \\
30.5 & 9.38 & 0.308 \\
40.45 & 12.43 & 0.307 \\
50.36 & 15.48 & 0.307 \\
100.67 & 31.03 & 0.308 \\
200.66 & 62.09 & 0.309 \\
\hline & Average & 0.308 \\
\hline \hline
\end{tabular}

\section{ACKNOWLEDGEMENT}

This work has been conducted in National Center for Micro- and Nanofabrication (DTU Danchip) and DTU Electrical Engineering. This project is a part of TinyPower project which is funded by Innovation Fund (No. 67-2014-1).

\section{REFERENCES}

[1] D. Bandyopadhyay and J. Sen, "Internet of things: Applications and challenges in technology and standardization," in Wirel. Pers. Commun., 2011, vol. 58, no. 1, pp. 49-69.

[2] D. Miorandi, S. Sicari, F. De Pellegrini, and I. Chlamtac, "Internet of things: Vision, applications and research challenges," Ad Hoc Networks, vol. 10, no. 7. pp. 1497-1516, 2012.

[3] S. Li, L. Da Xu, and S. Zhao, "The internet of things: a survey," Inf. Syst. Front., vol. 17, no. 2, pp. 243-259, 2015.

[4] G. Sauerländer, D. Hente, H. Radermacher, E. Waffenschmidt, and J. Jacobs, "Driver electronics for LEDs," in Conf. Rec. IEEE 41st IAS Annu. Meet., 2006, vol. 5, pp. 2621-2626.

[5] S. C. O'Mathuna, "PwrSiP power supply in package power system in package," in 2016 Int. Symp. 3D Power Electron. Integr. Manuf., 2016, pp. 1-21.

[6] F. Waldron, R. Foley, J. Slowey, A. N. Alderman, B. C. Narveson, and S. C. Ó Mathúna, "Technology roadmapping for power supply in package (PSiP) and power supply on chip (PwrSoC)," IEEE Trans. Power Electron., vol. 28, no. 9, pp. 4137-4145, 2013.

[7] M. Araghchini et al., "A Technology Overview of the PowerChip Development Program," IEEE Trans. Power Electron., vol. 28, no. 9, pp. 4182-4201, 2013.

[8] S. C. Ó. Mathúna, T. O’Donnell, N. Wang, and K. Rinne, "Magnetics on silicon: An enabling technology for power supply on chip," IEEE Trans. Power Electron., vol. 20, no. 3, pp. 585-592, 2005.

[9] C. Ó. Mathúna, N. Wang, S. Kulkarni, and S. Roy, "Review of integrated magnetics for Power Supply on Chip (PwrSoC)," IEEE Trans. Power Electron., vol. 27, no. 11, pp. 4799-4816, 2012.

[10] D. Disney and Z. J. Shen, "Review of silicon power semiconductor technologies for power supply on chip and power supply in package applications," IEEE Trans. Power Electron., vol. 28, no. 9, pp. 41684181, 2013.

[11] E. J. Brandon, E. Wesseling, V. White, C. Ramsey, L. Del Castillo, and U. Lieneweg, "Fabrication and characterization of microinductors for distributed power converters," IEEE Trans. Magn., vol. 39, no. 4 II, pp. 2049-2056, 2003.

[12] J. Li, V. Tseng, Z. Xiao, and H. Xie, "A High-Q In-Silicon Power Inductor Designed for Wafer-Level Integration of Compact DC-DC Converters," IEEE Trans. Power Electron., vol. 32, no. 5, pp. 1-1, 2016.

[13] C. R. Sullivan and S. R. Sanders, "Design of microfabricated transformers and inductors for high-frequency power conversion," IEEE Trans. Power Electron., vol. 11, pp. 228-238, 1996.

[14] N. Wang, T. O\&apos;Donnell, S. Roy, P. McCloskey, and C. O\&apos;Mathuna, "Micro-inductors integrated on silicon for power supply on chip," J. Magn. Magn. Mater., vol. 316, no. 2 SPEC. ISS., pp. e233-e237, Sep. 2007.

[15] T. Liakopoulos, A. Panda, M. Wilkowski, and A. Lotfi, "Manufacturing Development of a New Electroplated Magnetic Alloy Enabling Commercialization of PwrSoC Products," in Int. Work. Power Supply Chip, 2012.

[16] N. Sturcken et al., "A 2.5D integrated voltage regulator using coupledmagnetic-core inductors on silicon interposer," IEEE J. Solid-State Circuits, vol. 48, no. 1, pp. 244-254, 2013.

[17] S. X. Wang, "Fabrication and Analysis of High-Performance Integrated Solenoid Inductor With Magnetic Core," IEEE Trans. Magn., vol. 44, no. 11, pp. 4089-4095, Nov. 2008.

[18] D. Dinulovic, M. Haug, J. Thone, and M. C. Wurz, "Microtransformer / Microinductor on Silicon for Point-of-Load High Frequency Power Applications," Int. Work. Power Supply Chip, 2016.

[19] A. Camarda, E. Macrelli, M. Tartagni, R. P. Paganelli, and A. Romani, "Design and Fabrication of Bond Wire Micro-Magnetics with LTCC core," in Int. Work. Power Supply Chip, 2016, pp. 1-38.

[20] J. Kim, J.-K. Kim, M. Kim, F. Herrault, and M. G. Allen, "Microfabrication of toroidal inductors integrated with nanolaminated ferromagnetic metallic cores," J. Micromech. Microeng., vol. 23, no. 11, p. 114006 , Nov. 2013.

[21] R. Meere, T. O’Donnell, S. Kulkarni, S. Roy, and S. C. O’Mathuna, "Magnetic-Core and Air-Core Inductors on Silicon: A Performance Comparison up to $100 \mathrm{MHz}$," IEEE Trans. Magn., vol. 47, no. 10, pp. 4429-4432, Oct. 2011.

[22] C. D. Meyer, S. S. Bedair, B. C. Morgan, and D. P. Arnold, "Influence of layer thickness on the performance of stacked thick-film copper aircore power inductors," IEEE Trans. Magn., vol. 48, no. 11, pp. 44364439, 2012. 
[23] J. Y. Park and M. G. Allen, "High Q spiral-type microinductors on silicon substrates," IEEE Trans. Magn., vol. 35, no. 5 PART 2, pp. 3544-3546, 1999.

[24] J. Kim, F. Herrault, X. Yu, M. Kim, R. H. Shafer, and M. G. Allen, "Microfabrication of air core power inductors with metal-encapsulated polymer vias," J. Micromech. Microeng., vol. 23, no. 3, p. 35006, Mar. 2013.

[25] U. Schürmann et al., "Fabrication of toroidal microinductors for RF applications," in IEEE Trans. Magn., 2009, vol. 45, no. 10, pp. 47704772 .

[26] L. Gu and X. Li, "High-Q solenoid inductors with a CMOS-compatible concave-suspending MEMS process," J. Microelectromechanical Syst., vol. 16, no. 5, pp. 1162-1172, 2007.

[27] X. Yu, M. Kim, F. Herrault, C.-H. Ji, J. Kim, and M. G. Allen, "SiliconEmbedding Approaches to 3-D Toroidal Inductor Fabrication," $J$. Microelectromechanical Syst., vol. 22, no. 3, pp. 580-588, Jun. 2013.

[28] J. M. Burkhart, R. Korsunsky, and D. J. Perreault, "Design Methodology for a Very High Frequency Resonant Boost Converter," IEEE Trans. Power Electron., vol. 28, no. 4, pp. 1902-1909, 2010.

[29] Y. Nour, Z. Ouyang, A. Knott, and I. H. H. Jørgensen, "Design and Implementation of High Frequency Buck Converter Using Multi-Layer PCB Inductor," 42nd Annu. Conf. IEEE Ind. Electron. Soc., pp. 1313$1317,2016$.

[30] Y. Nour, A. Knott, and I. H. H. Jørgensen, "Investigating Enhancement Mode Gallium Nitride Power FETs in High Voltage, High Frequency Soft Switching Converters," in Int. Conf. Power Electron. Mach. Drives, 2016, pp. 1-5.

[31] M. K. Kazimierczuk, "Class D Current-Driven Rectifiers for Resonant DC/DC Converter Applications," IEEE Trans. Ind. Electron., vol. 38, no. 5, pp. 344-354, 1991.

[32] M. K. Kazimierczuk and D. Czarkowski, Resonant Power Converters, vol. 7, no. June. 2012

[33] K. Peng and E. Santi, "Class E Resonant Inverter Optimized Design for High Frequency ( $\mathrm{MHz}$ ) Operation Using eGaN HEMTs," in Appl. Power Electron. Conf. Expo., 2015, pp. 2469-2473.

[34] J. M. Rivas, Y. Han, O. Leitermann, A. D. Sagneri, and D. J. Perreault, "A high-frequency resonant inverter topology with low-voltage stress," IEEE Trans. Power Electron., vol. 23, no. 4, pp. 1759-1771, 2008.

[35] A. Knott et al., "Evolution of Very High Frequency Power Supplies," IEEE J. Emerg. Sel. Top. Power Electron., vol. 2, no. 3, pp. 386-394, Sep. 2014.

[36] M. Madsen, A. Knott, and M. A. E. Andersen, "Low power very high frequency switch-mode power supply with $50 \mathrm{v}$ input and $5 \mathrm{v}$ output," IEEE Trans. Power Electron., vol. 29, no. 12, pp. 6569-6580, 2014.

[37] J. A. Pedersen, M. P. Madsen, A. Knott, and M. A. E. Andersen, "Selfoscillating Galvanic Isolated Bidirectional Very High Frequency DC-DC Converter," in Appl. Power Electron. Conf. Expo., 2015, pp. 1974-1978.

[38] M. P. Madsen, A. Knott, and M. A. E. Andersen, "Very high frequency half bridge DC/DC converter," 2014 IEEE Appl. Power Electron. Conf. Expo. - APEC 2014, pp. 1409-1414, 2014.

[39] H. T. Le, I. Mizushima, P. T. Tang, Z. Ouyang, F. Jensen, and A. Han, "Fabrication of 3D Air-core MEMS Inductors for High Frequency Power Electronic Applications," Microsystems Nanoeng., vol. 3, 2017, DOI. 10.1038/micronano.2017.82.

[40] E. Shkondin et al., "Fabrication of high aspect ratio $\mathrm{TiO}_{2}$ and $\mathrm{Al}_{2} \mathrm{O}_{3}$ nanogratings by atomic layer deposition," J. Vac. Sci. Technol. A Vacuum, Surfaces, Film., vol. 34, no. 3, p. 31605, 2016.

[41] C. R. Sullivan, S. Prabhakaran, S. Lu, C. R. Sullivan, W. Li, and S. Prabhakaran, "Design and Fabrication of Low-Loss Toroidal Air-Core Inductors," no. June, pp. 1754-1759, 2007.

[42] M. Araghchini et al., "Modeling and Measured Verification of Stored Energy and Loss in MEMS Toroidal Inductors," vol. 50, no. 3, pp. 2029-2038, 2014

[43] G. Zulauf, W. Liang, and J. Rivas-davila, "A Unified Model for HighPower, Air-Core Toroidal PCB Inductors," in IEEE Work. Control Model. Power Electron., 2017.

[44] R. Anthony, E. Laforge, D. P. Casey, J. F. Rohan, and C. O'Mathuna, "High-aspect-ratio photoresist processing for fabrication of high resolution and thick," J. Micromech. Microeng., vol. 26, no. 10, p. 105012,2016

[45] H. T. Le et al., "High-Q 3D Microfabricated Magnetic-core Toroidal Inductors for Power Supplies in Package," unpublished.

[46] J. H. Dellinger, "The temperature coefficient of resistance of copper," $J$. Franklin Inst., vol. 170, no. 3, pp. 213-216, 1910.

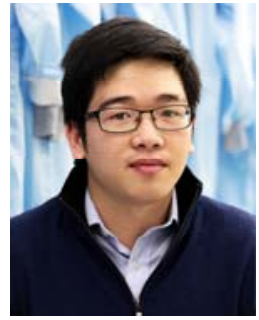

Hoa Thanh Le (S'15) received the B.Sc. degree in Electronics and Telecommunications from Ho Chi Minh University of Technology, Vietnam, in 2012 and the M:Sc. degree in Microsystem Engineering from University College of Southeast Norway, Norway, in 2014. He is currently pursuing the $\mathrm{PhD}$ degree in Micro and Nanofabrication at Technical University of Denmark. His research interests include micro- and nanofabrication, passive components, and high frequency magnetics.

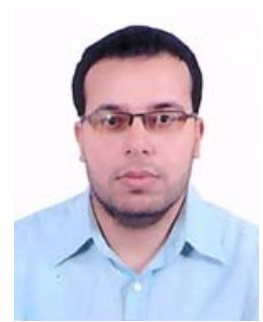

Yasser Nour (S'07, M'17) received the B.Sc. and M.Sc. degrees in Electrical Engineering from South Valley University, Egypt in 2007 and 2011 respectively. He was a research engineer at Enpirion Inc., a staff engineer at Altera's Egypt Technology Center, and a staff engineer at Symmid Corporation Sdn. Bhd. in Malaysia. He is currently pursuing the $\mathrm{PhD}$ in electrical engineering at Technical University of Denmark. His research interests include analog integrated circuits design, integrated power converters, high voltage low power converters, integrated magnetics and passive components.

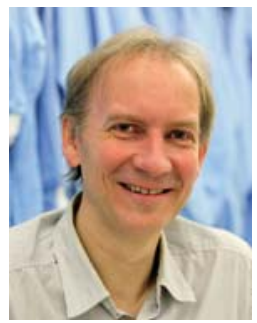

Flemming Jensen received the Ph.D. degree in Physics from the Department of Physics and Astronomy at Aarhus University, Denmark, in 1992. From 1992 until 1997 he worked as a researcher at the newly established cleanroom facility, Microelectronics Center (MIC) - from 2004 renamed DTU Danchip - at the Technical University of Denmark establishing and developing new fabrication technologies in etching and thin film deposition mainly for the silicon based platform. From 1997 he has been an Associate Professor conducting and supporting research projects related to micro- and nanofabrication within various research topics. From 2004 he has been member of the management at DTU Danchip heading the Process Engineering group. In the later years his main focus has been on advanced high density plasma etching techniques for many different material platforms and establishing atomic layer deposition for conformal growth of very thin layers.

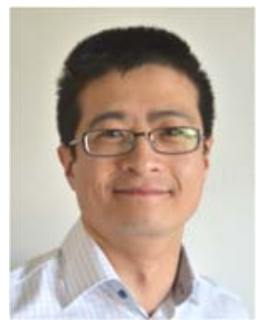

Anpan Han (M' 12) received the B.Sc. and M.Sc. degree in biophysics from the Niels Bohr Institute, University of Copenhagen, Denmark, in 2002. He received the Ph.D. degree in Micro and Nanotechnology from Institute of Microtechnology (now part of EPFL), Université de Neuchâtel, Switzerland in 2006. Currently, he is an assistant professor at Danchip, Technical University of Denmark since 2014. His research is in nanofabrication technology and science, with focus in diamond MEMS, complex MEMS process integration and electron beam lithography

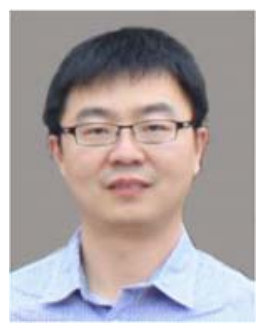

Ziwei Ouyang (S'07, M'11) received the B.S degree in electrical engineering from the Naval University of Engineering, Wuhan, China, in 2004, the M.S degree from the Tianjin University of Technology, Tianjin, China, in 2007, and the Ph.D. degree from the Technical University of Denmark (DTU), Denmark, in 2011. He worked as Postdoctoral Researcher and assistant professor in the Department of Electrical Engineering at DTU from 2011 to 2016 and is currently associate professor in the same department. His research areas focus on highfrequency planar magnetics modeling and integration, high-density highefficiency power converters, PV battery energy storage system, and wireless charging etc. He has over 50 peer-reviewed journal and conference publications and currently he is the holder of five US/EP/PCT patents. He received the Young Engineer Award at PCIM Asia 2014 and Best Paper Awards in ECCE Asia conferences in 2010 and 2012, respectively. He is an IEEE senior member. 


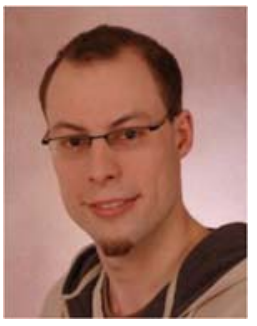

Arnold Knott (M’10) received the DiplomIngenieur $(\mathrm{FH})$ degree from the University of Applied Sciences in Deggendorf, Germany, in 2004.

From 2004 until 2009 he has been working with Harman/Becker Automotive Systems GmbH in Germany and USA, designing switch-mode audio power amplifiers and power supplies for automotive applications. In 2010 he earned the Ph.D. degree from the Technical University of Denmark, Kongens Lyngby, Denmark working on a research project under the title "Improvement of out-ofband Behaviour in Switch-Mode Amplifiers and Power Supplies by their Modulation Topology". From 2010 to 2013 he was Assistant Professor and since 2013 Associate Professor at the Technical University of Denmark. His interests include switch-mode audio power amplifiers, power supplies, active and passive components, integrated circuit design, acoustics, radio frequency electronics, electromagnetic compatibility and communication systems. 